\title{
Influence of Tetradecyl Methacrylate-N- $\alpha-$ methacrylamide Copolymers as Pour Point Depressants on the Cold Flow Property of Diesel Fuel
}

Suya Yin ${ }^{1}$, Taishun Yang ${ }^{1}$, Yuan Xue ${ }^{1}$, Maiying Xie ${ }^{1}$, Fengfei Chen ${ }^{1}$, Hualin Lin ${ }^{1, *}$, Bin $\mathrm{Dai}^{2}$, Feng Gao ${ }^{1, *}$, Sheng $\operatorname{Han}^{1,2, *}$

${ }^{1}$ School of Chemical and Environmental Engineering, Shanghai Institute of Technology, Shanghai 201418, China

${ }^{2}$ School of Chemistry and Chemical Engineering, Shihezi University, Shihezi, Xinjiang 832000, China

* Corresponding author: Tel:+86-021-60873560; Email address: hansheng654321@sina.com (Sheng Han);

gaofeng406@hotmail.com (Feng Gao); 1h16534@163.com (Hualin Lin).

\section{Supporting Information}

\section{GC-MS ANALYSIS}

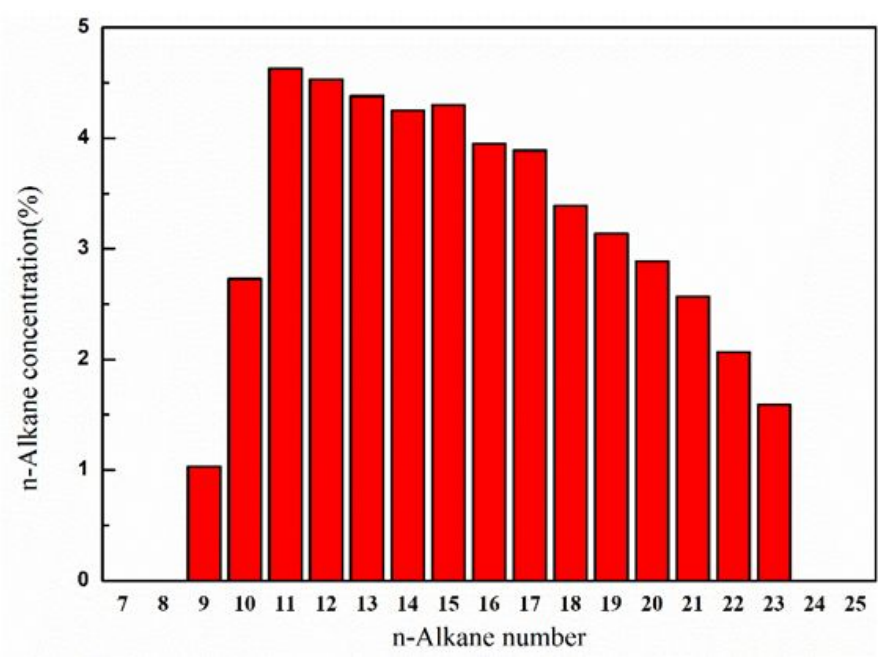

Figure S1. Carbon number distribution of diesel fuel sample.

The compositions of 0\# diesel fuel were analyzed by using a Shimadzu GC-MS QP 2010SE (Japan). The operate condition of GC-MS were as follow: the capillary was procedurally increased from 60 to $260{ }^{\circ} \mathrm{C}$ at $5{ }^{\circ} \mathrm{C} / \mathrm{min}$, both the interface and injector temperature were $290{ }^{\circ} \mathrm{C}$, used the helium as the carrier gas and the diffluent ratio was 100:1. 
the carbon number distribution of the total wax in diesel fuel is broad (C9-C23), and the average carbon number of n-paraffin is 16.1 . The physicochemical characteristics of diesel fuel is listed in Table S1. Due to its higher content of n-paraffin (49.24 wt.\%). The SP and CFPP of diesel fuel are $-13{ }^{\circ} \mathrm{C}$ and $-2{ }^{\circ} \mathrm{C}$, respectively. As shown in Table S1, the density was measured by using a SYD-1884 Petroleum Product Density Tester according to standard method SH/T0604. The kinematic viscosity of samples was measured using Petroleum Product Viscosity Tester according to standard method GB/T265. The flash point of diesel as measured using a SYD-261 Closed Flash Tester according to standard method GB/T261. The acid value of samples was measured using a ZD-3A Automatic Potentiometric Titrator according to standard method GB/T258.

Table S1. Physical and chemical characteristics of diesel fuel.

\begin{tabular}{lcc}
\hline Test & Method & Diesel fuel \\
\hline Density at $20{ }^{\circ} \mathrm{C}(\mathrm{kg} / \mathrm{m} 3)$ & $\mathrm{SH} / \mathrm{T} 0604[1]$ & 810.6 \\
Kinematic viscosity at $40{ }^{\circ} \mathrm{C}(\mathrm{mm} 2 / \mathrm{s})$ & $\mathrm{GB} / \mathrm{T} 265[2]$ & 3.526 \\
Flash point $\left({ }^{\circ} \mathrm{C}\right)$ & $\mathrm{GB} / \mathrm{T} 261[3]$ & 80 \\
Cold filter plugging point $\left({ }^{\circ} \mathrm{C}\right)$ & $\mathrm{ASTM}$ D6371 [4] & -2 \\
Solid point $\left({ }^{\circ} \mathrm{C}\right)$ & $\mathrm{GB} / \mathrm{T} 510[5]$ & -13 \\
Saturated hydrocarbon $($ wt. \%) & GC-MS & 87.3 \\
Aromatic hydrocarbon $(w t . \%)$ & GC-MS & 12.7 \\
Acid value (mg of KOH/100 ml) & GB/T258 [6] & 1.75 \\
\hline
\end{tabular}

\section{OTHER FUEL PROPERTIES MEASUREMENTS.}

These monomers and copolymers were analyzed between potassium bromide by Nicolet iN10 Fourier Transform Infrared spectrometer (FTIR, America). The scanning range of $400 \mathrm{~cm}^{-1}$ and $4000 \mathrm{~cm}^{-1}$ for 32 scans. 1H NMR experiments were recorded on AVANCE III $500 \mathrm{MHz}$ spectrometer (Switzerland), quipped with a $5 \mathrm{~mm}$ probe in deuterated chloroform with tetramethyl silane as the internal standard. The thermal stability of polymers was confirmed by the SHIMADZU DTG-60 Thermo Gravimetric Analyzer (TGA, Japan). The samples were weighed about $10 \mathrm{mg}$, the temperature heat from 0 to $700{ }^{\circ} \mathrm{C}$ at the heating rate of $10{ }^{\circ} \mathrm{C} / \mathrm{min}$.

The molecular weights and polydispersity were determined using Gel Permeation Chromatography (GPC) (HLC-8320 GPC, Japan). GPC to determine the molecular weight and 
polydispersity index of the prepared PPD. THF was the mobile phase and the flow rate was 1 $\mathrm{mL} / \mathrm{min}$. Polystyrene is used as a standard material, and the measurement results are shown in Table S2. When the molecular weight of the pour point depressant is between 4000 and $100,000 \mathrm{~g} / \mathrm{mol}$, it can show excellent effects. Table S2 shows that the weight average molecular weight (Mw) and number average molecular weight $(\mathrm{Mn})$ of PPD are $5.97 \times 10^{4}$ to $9.61 \times 10^{4}$, and $2.86 \times 10^{4}$ to $3.50 \mathrm{x}$ $10^{4}$, the polydispersity index $(\mathrm{Mw} / \mathrm{Mn})$ is used to measure the molecular weight distribution of PPD. The polydispersity index (Mw/Mn) is 2.033 to 4.730 , respectively. Thus, it is concluded that the degree of polymerization of the copolymer is within an optimal range, and has the optimum applicability as PPDs of diesel fuel.
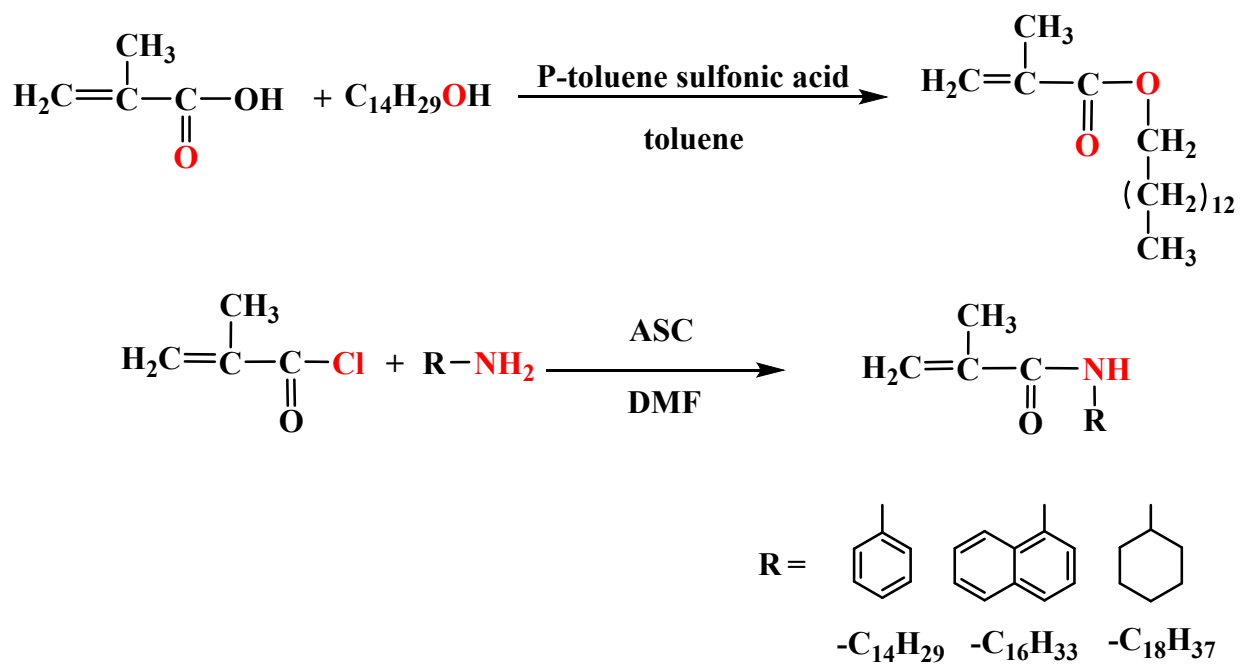

Figure S2. Synthetic routines of monomers.

Table S2. Molecular weight of copolymers.

\begin{tabular}{llll}
\hline Copolymer & $\mathrm{Mw}^{\mathrm{a}}(\mathrm{g} / \mathrm{mol})$ & $\mathrm{Mn}^{\mathrm{b}}(\mathrm{g} / \mathrm{mol})$ & $\mathrm{Mw} / \mathrm{Mn}$ \\
\hline $\mathrm{C}_{14}$ MC-NML-phenly (1:1) & 88,876 & 30,946 & 2.872 \\
$\mathrm{C}_{14}$ MC-NML-phenly (3:1) & 96,132 & 32,119 & 2.993 \\
$\mathrm{C}_{14}$ MC-NML-phenly (6:1) & 91,120 & 28,872 & 3.156 \\
$\mathrm{C}_{14}$ MC-NML-phenly (9:1) & 82,988 & 33,546 & 2.474 \\
$\mathrm{C}_{14}$ MC-NML-phenly (12:1) & 96,035 & 20,302 & 4.730 \\
$\mathrm{C}_{14}$ MC-NML-phenly (15:1) & 59,743 & 29,387 & 2.033 \\
\hline
\end{tabular}

Note: $\mathrm{Mw}^{\mathrm{a}}=$ Weight-average molecular weight

$\mathrm{Mn}^{\mathrm{b}}=$ Number-average molecular weight

\section{H NMR SPECTRA OF OTHER COPOLYMERS.}



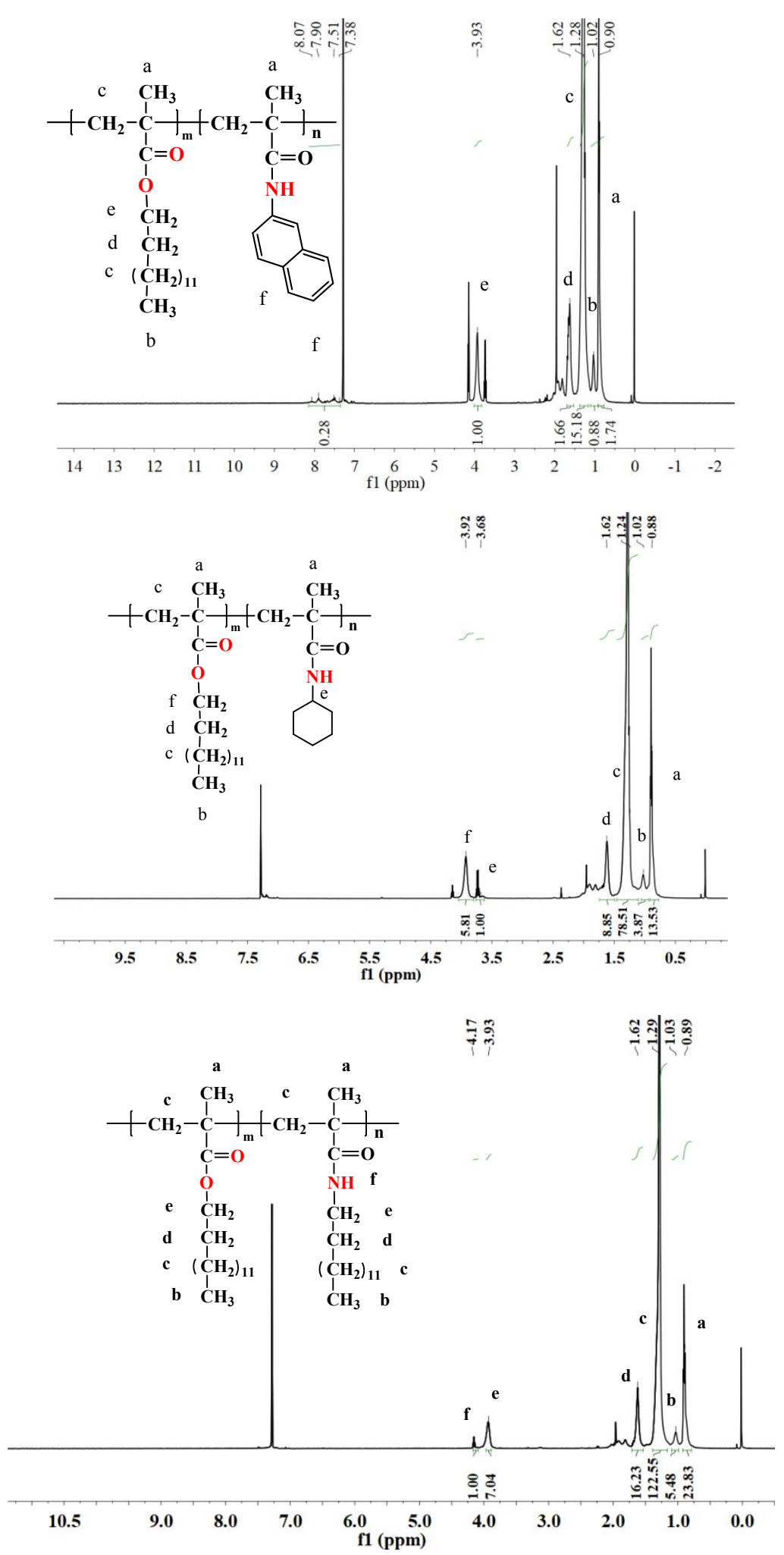

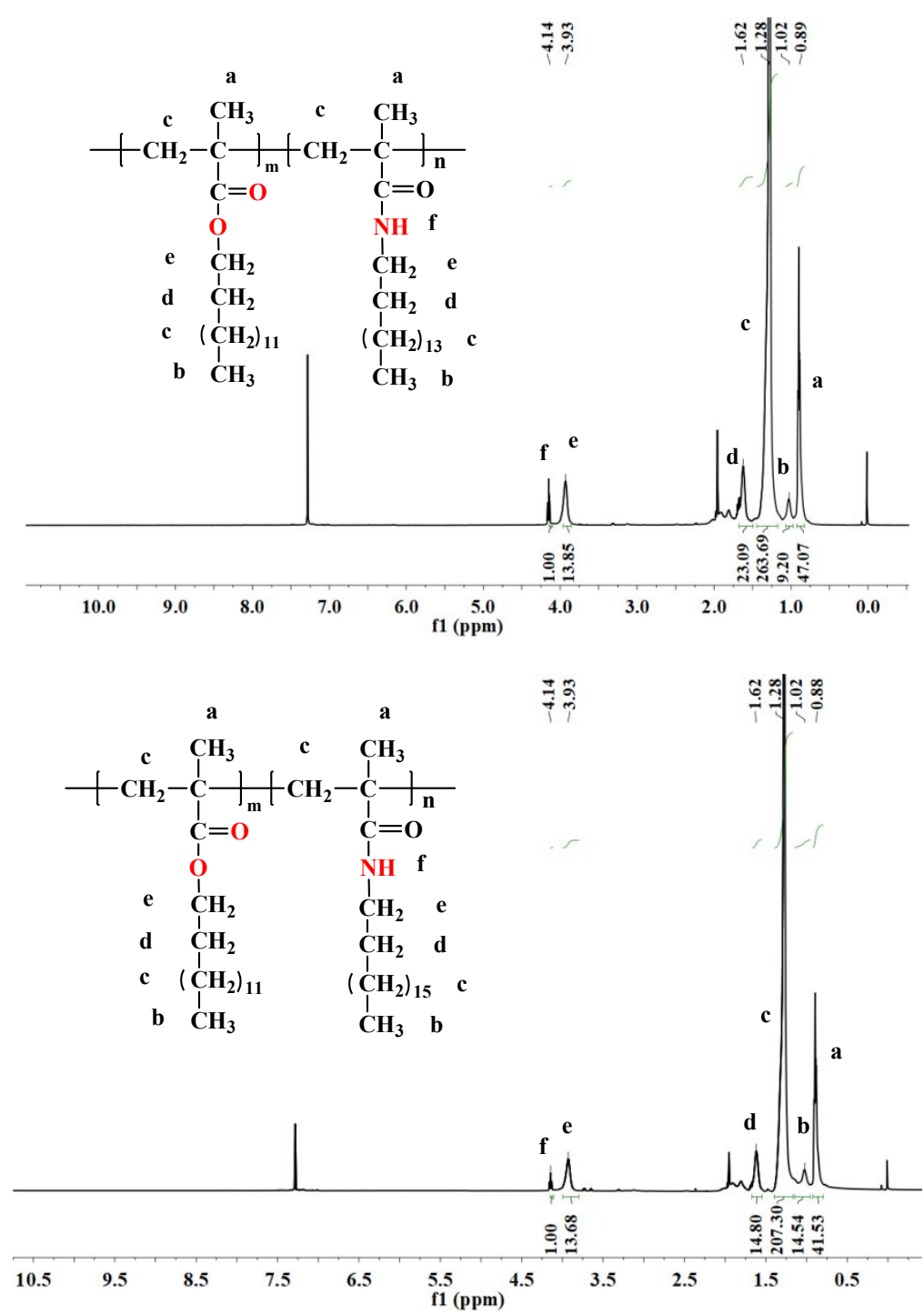

\section{REFERENCE:}

1. ASTM D6371-17a., Standard test method for cold filter plugging point of diesel and heating fuels., ASTM International., West Conshohocken, PA, 2017.

2. GB/T258-2016, Standard test method for determination of acidity of light petroleum products, 2016.

3. GB/T261-2008., Standard test method for determination of flash point-PenskyMartens closed cup method., 2008.

4. GB/T265-1988., Standard test method for kinetic viscosity measurement and kinetic viscosity calculation of petroleum products., 1988. 
5. GB/T510-2018, Standard Press of China, Determination of solidification point for petroleum products, 2018.

6. SH/T0604-2000., Standard test method for density measurement of crude oil and petroleum products (U-shaped vibration tube method)., 2000.

In order to minimize the potential occasional errors, all samples were determined in triplicates. The results were averaged as the final values that are depicted in the tables and figures. 